\title{
The Basic and Psychological Needs of Adult Refugees in Hong Kong: A Preliminary Report
}

\author{
Xin Yi Siah \\ United Christian College, Kowloon East, HONG KONG SAR \\ Wai Ling Kwok \\ St. Paul's Secondary School, HONG KONG SAR \\ Poh Chua Siah \\ Universiti Tunku Abdul Rahman, Kampar Campus, MALAYSIA
}

Received: 19 Apil 2020 • Accepted: 26 June 2020 - Published Online: 21 July 2020

\section{Abstract}

\begin{abstract}
The problems faced by refugees in Hong Kong are seldom reported and understood by the general population. Through Maslow's hierarchy of needs, this preliminary report aims to explore the views of adult refugees on the support provided by the Hong Kong government, and whether these supports meet their basic and psychological needs or not. Purposive sampling method was used to recruit five adult refugees for an in-depth interview. Thematic analysis was used to analyze the transcripts of the interview. The results showed that the assistance from the government are able to meet their basic needs but not their psychological needs. Some express their psychological needs to move forward but feel helpless due to the policy that they are not permitted to find a job or study. It is suggested the government to revise the policy from a shortterm to a long-term consideration, as many of them have been staying in Hong Kong for a long period of time, and some of them even have set up their own family in Hong Kong.
\end{abstract}

Keywords: Refugees, Hong Kong, policy, psychological needs.

\section{Introduction}

Under the influence of globalization, widespread conflicts such as wars and violations of human rights make the migration and refugee problem an international issue. According to the United Nations High Commissioner for Refugees (2018), there were 70.8 million people forced to displace worldwide. The refugee problem is a rising and significant issue that also affects Hong Kong. As of August 2015, there are over 9,900 asylum seekers, over half of which belong to Pakistan, India and Bangladesh (Tinoco, 2015). The grant for asylum in Hong Kong is difficult, as there have been only 55 accepted claims since 2009 (Regan, 2016), while compared to the $27 \%$ of the average recognition rate for refugees, the recognition rate in Hong Kong is $0.16 \%$ (Tinoco, 2015).

(C) Authors. Terms and conditions of Creative Commons Attribution 4.0 International (CC BY 4.0) apply. Correspondence: Dr. Poh-Chua Siah, University Tunku Abdul Rahman, Faculty of Arts and Social Science, Department of Psychology and Counseling, Kampar Campus, Jalan Universiti, Bandar Barat, 31900 Kampar, Perak, MALAYSIA. E-mail: siahpc@utar.edu.my. 
The government of the Hong Kong Special Administrative Region of the People's Republic of China (HKSAR) offers assistance towards the protection claimants via the Asylum Seeker and Torture Claimant Programme, which include asylum-seekers, refugees and torture claimants (ASRs). There are two separate systems to handle the application from ASRs, the first is immigration authorities and the second is UNHCR's sub-office in Hong Kong SAR. The functions of the two systems seem to be overlapping and operating in parallel (Loper, 2010).

- Most interviewees express their psychological needs to move forward.

- Some interviewees feel helpless as they are not permitted to find a job or study.

- The assistances from government should be revised to meet the long-term needs.

In 2006, the Hong Kong SAR government established the non-governmental organization International Social Services to assist refugees in Hong Kong, under which they provided for their basic needs through the Asylum Seeker and Torture Claimant Programme (The Government of the Hong Kong Special Administrative Region, 2017). The assistance consists of $\$ 1,200$ for food, $\$ 1,500$ in rent allowance and $\$ 500$ for other utilities and transport (Vision First, 2016). This is to meet their basic needs and prevent refugees from "sleeping on the street", be "seriously hungry", or being unable to "satisfy the most basic requirement of hygiene" (Legislative Council, Hong Kong SAR Government, 2015; Vision First, 2013). The aim is to "prevent a magnet effect" which could "have serious implications" on the sustainability of current support systems and immigration control" (Legislative Council, Hong Kong SAR Government, 2013). They are not allowed to work and are required to report to the Immigration Department every two months.

The lack of a comprehensive programme in dealing with refugees by the Hong Kong SAR government may be due to their concern of creating a "magnet effect." (Legislative Council, Hong Kong SAR Government, 2014), or receiving an overwhelming surge of refugees and its subsequent consequences. This can be related to the Vietnamese boat saga in the 1980s, in which the government spent "HK\$8.7 billion in providing assistance to them" (Legislative Council, Hong Kong SAR Government, 2006). Furthermore, Hong Kong SAR government do not plan to extend the 1951 Refugee Convention to Hong Kong (Loper, 2010) as the government believes that the extending will trigger a drastic surge of asylum seekers, and thus insisting towards the United Nations Committee for Torture that the Hong Kong SAR government has a firm policy not to grant asylum (Security Bureau, Hong Kong SAR Government, 2009a, 2009b). Under the system, asylum seekers have challenged Hong Kong's lack of adequate refugee policies and many, including several United Nations Human Rights bodies, have similarly criticized the government consistently, arguing that the city should ratify the relevant treaties, adopting a more "humanrights approach" in implementing policies (T. Cheung, 2016; Chiu, 2012).

Under the current government assistance, refugees are allocated $\$ 1,500$ in rent allowance, which is directly transferred to the landlords. However, the monthly rental allowance is not adjusted periodically to changes in inflation or Consumer Price Index (Refugee Concern Network, 2013a), leading to increasingly worse living conditions as the rental prices increases, especially as the city has one of the highest real estate costs worldwide (The Telegraph, 2020). Furthermore, these costs do not include miscellaneous expenses, such as electricity and water fees (Refugee Concern Network, 2013b). As such, this leads to a decline in housing conditions, as the rent allowance is deficient in guaranteeing affordable, secure, physically safe and habitable housing.

Therefore, many refugees live in small and poorly furnished accommodations in low income districts, most of which are less than 50 square feet without any windows, air conditioning, or heaters, and many must also cook inside their rooms due to space limitations (Shum, 2011). According to the Refugee Concern Network (2013b), 76\% of refugees have challenges with space 
or physical accessibility. To pay for rent, they tend to support each other, pooling their rental allowances together. Furthermore, many Hong Kong residents are unwilling to rent rooms to 'foreigners', as they are perceived as troublemakers (Shum, 2011). This is due to racial discrimination, cultural and language barriers, as well as a lack of HKID (Legislative Council, Hong Kong SAR Government, 2012). When refugees search for accommodation on their own, they encounter unpleasant attitudes and are asked to leave (Shum, 2011).

Due to the knowledge of refugees and their conditions in the city is not very wellknown amongst the general public, many citizens held a hostile perception towards refugees. According to a study conducted by the University of Hong Kong Public Opinion Programme, only 4.7\% of Hongkongers hold positive views towards asylum seekers and refugees, with those holding negative views stating that they made "society unsafe" and created a "disturbance in the community.". In addition, the public have misinformed concepts about the asylum seekers and refugees in Hong Kong (K. Cheung, 2016).

According to a report by Health in Action (n.d.), besides government assistance on rent, refugees are able to attend basic medical services at public hospitals with their fees waived. However, to do so, they must sign up their names on a list, seeking a waiver each time they need to access publicly-accessible medical services. Furthermore, other factors also hinder their access to basic healthcare. Apart from financial constraints, these include language barriers, cultural differences and a lack of awareness of health needs. As a result, this could lead to misunderstandings regarding the services available and information gaps about their medical condition (Refugee Concern Network, 2013b).

In terms of food, refugees are given $\$ 1200$ for their food and the food is prepared by the social welfare contractor based on the government's contract, now refugees are given food coupons that can only be used at certain food retailers (Lee, 2015). In terms of education, the Hong Kong SAR government provides education for refugees under the age of 18 , which is granted on a case-by-case basis (Carvalho, 2015), which is granted due to a variety of factors, including the likelihood that the student will be removed from Hong Kong. The refugee children are able to enter school when they are six years old (Carvalho, 2015).

Apart from language barriers, cultural differences and financial problems can also cause difficulties for children and their parents. Despite the available financial assistance provided by the Student Financial Assistance Agency, the aid tends to arrive later in the school year, not in the beginning when costs are most significant (Refugee Concern Network, 2013b). Besides, refugees are unable to be employed according to the Immigration Ordinance. According to the Hong Kong SAR Government, they are legally treated as 'overstayers'. Occasionally, they are allowed temporary permission to work by the Immigration Department discretionarily, but it is rarely granted in practice (Moy, 2013). If they are found working illegally, they are subjected to a maximum penalty of three years in prison with a \$50,00o fine (Hong Kong Refugee Advice Centre, 2013). However, to pay for utility charges and daily expenses, refugees work for licensed street hawkers by setting up hawker stalls, or illegally in Chungking Mansions (Mathews, 2007; Shum, 2011).

\section{Aims of the study}

From the views of Maslow's hierarchy of needs, besides basic needs, humans also have their psychological needs and self-fulfilment needs (McLeod, 2007). The basic needs are important to survive, such as the physiological and safety needs. The psychological needs are important to personal growth, such as love and esteem, and self-actualization is a being need. Being needs are different from the deficit needs that include the basic needs and psychological needs. Deficit needs are motivating factors that make people act in a certain direction, and the 
X. Y. Siah, W. L. Kwok \& P. C. Siah - The Basic and Psychological Needs of Adult Refugees in ...

people will not perform the action when their deficit needs are temporarily satisfied (Poston, 2009).

Based on the theory of Maslow's hierarchy of needs, the Hong Kong SAR government's policy towards refugees is more relevant to meet the basic needs without the consideration of their psychological needs. It can be expected that refugees are unable to occupy time meaningfully and productively (Refugee Concern Network, 2013b). A survey conducted by Saunders et al. (1998) which recruited 157 undergraduates from an Australian university have shown that respondents who are low in the levels of these five needs are more likely to have the problems of depression, anxiety and anger expression.

Accordingly, this report aims to use Maslow's hierarchy of needs as a framework to examine the extent that the policy meets the basic and psychological needs of refugees, and their responses to the policy. Through the findings of the report, NGOs and policy makers may design strategies to improve the basic and psychological needs of those refugees who have been staying in Hong Kong for a long time.

\section{Method}

\subsection{Participants}

Five refugees were recruited for the interview. The number of interviewees falls within the recommended range that for those participants having a high level of knowledge and expertise in the specific area of research, four to five interviews would be sufficient (Bohari, Skitmore, Xia \& Teo, 2017). Their demographic profiles were shown in Table 1.

Table 1. Profile of interviewees

\begin{tabular}{lllll}
\hline Interviewees & Age & Gender & Nationality & Staying In HK \\
\hline 1 & $26-31$ & Male & Sri Lanka & 9 \\
2 & $32-48$ & Male & Mumbai & 7 \\
3 & $32-48$ & Male & Cameroon & 12 \\
4 & $26-31$ & Male & Iran & 7 years \\
5 & $26-31$ & Female & Ghana & 6 years \\
\hline
\end{tabular}

\subsection{Interview questions}

Ten semi-structure questions were prepared for the interview. Four questions were to collect their demographic information, such as their age, gender, country of origin and the duration they have been in Hong Kong. Other six questions were to understand their physical conditions, such their living conditions ("how about your living conditions?"), healthcare ("How about healthcare?"), education ("Do you have the opportunity to work?")and employment ("Do you have the opportunity to study?"); and their psychological conditions ("when you came here, how did you feel?"), and their views on government's policies and assistance on refugees ("Can you tell me what you think about government assistance on refugees?")

\subsection{Procedure}

Purposive sampling method was used to recruit the interviewees, that only adult refugees who had stayed in Hong Kong not less than one year were invited. Invitation email was sent to the managers of those NGOs based on the information collected from the internet. In the 
invitation email, the aim of the interview was explained and a sample of interview questions was attached. Since no reply has been received in the first two weeks, a follow up email was resent to these organizations. A NGO has replied and agreed to arrange the interview. Five refugees accepted the interview. They were interviewed according to the date and time arranged by the NGO. Since some interviewees refused to record their interviews, their transcripts were prepared based on the notes taken during the interview. The duration of each interview is about 30 minutes.

\subsection{Data analysis}

The interview data analysis using the thematic process follows the five stages of qualitative analysis proposed by Miles and Huberman (Huberman \& Miles, 2002). The first stage is to organize the data, followed by categorizing ideas and concepts, building themes in the data, validating the data and searching plausible explanations for the findings. While information obtained was analysed, extracted and conceptualized into categories and patterns, the relationships between the different categories were identified using codes which are labels assigned to the meaning of the descriptive information compiled (Glaser, 2001).

\section{Results}

Three themes were identified, which are financial needs, medical needs and psychological needs.

\subsection{Financial needs}

Most refugees received 3,000 HKD per month from the HK government (Interviewee 1: "1,200 for food, and rent 1,500"). Most interviewees feel that the financial support for rent is not enough due to the high renting cost in Hong Kong (Interviewee 1: "That's not enough. Because rent is getting high, and you have to pay more money"; Interviewee 3: "Where in Hong Kong can you find somewhere with that price?"). However, an interviewee mentioned that it can be due to the location that they stay (Interviewee2: "My family and I live in Yuen Long, where the rent is lower, so unlike some others I know, our living conditions are slightly better").

Besides rent, some mentioned the inconvenience of using food coupons as they can only use the coupon to buy food at certain shops (Interviewee 1: "You know the coupon? ParknShop coupon? And no any money, no any allowance, so we cannot buy what we want") (Interviewee 3: "The food coupon, so difficult to use because you have 12 coupons of 100. And you can only go to supermarket and buy things for $\$ 100$. If you only want bread, or if you only want vegetables, because you cannot just buy both things, and you can't use it straight away"), (Interviewee 3: "The freshness of the food, is you know, broken. Because most of us don't have fridge to keep the food").

\subsection{Medical needs}

Besides financial issues, some interviewees also mentioned the inconvenience of medical care, such as a long queue (Interviewee 4: "I had this severe pain [in my stomach], but when I went to visit a clinic, I was told to wait for 3 and a half years. Three and a half years. And when I saw a doctor, after 3 and a half years of waiting, he told me to wait another one and a half years to check up"), (Interviewee 1: "it takes a very long time, because you are there sick, but you have to line up at the welfare department, for them to give you to give you the money for you to pay. So with that waiver, you just have to take it now to the officer. So it's difficult, you know? If 
we have money, we can go to the hospital like everyone"). However, a refugee hold a neutral view on it (Interviewee 5: "I think it's not good, but not too bad also").

\subsection{Psychological needs}

Most refugees mentioned their need to work (Interviewee 1: "If government give me job, I can do job. But not allowed here, to do jobs. Not allowed. Give me a chance, I will be happy. More happy"), and the need to study (Interviewee 2: "I think the government should give us a chance to study- It's very important for our future. Many of us here are professionals, but the government doesn't give us a chance to work and contribute. Even if we want to study more, we cannot"), (Interviewee 3: "if the government gives us training we can be used in a kind of specific place, in a specific way, you know? That way we can be independent, we can serve by ourselvesHow we can be independent we are not really independent ourselves?"). Some show helpless feelings (Interviewee 4: "Why the person's trapped in Hong Kong, no permission to work, no permission to study, no permission to contribute to society in anyway...") and worry about the future of their children (Interviewee 5: "Even though some children can go to school, all cannot go to university"), (Interviewee 2: "I am a family man and I also worry about my daughter [Pauses] She wants to be a doctor, but the government only provides education for those under 18 . She can't go to study further, she can't go to university, she can't work. What will happen to her? What is in her future?"). Nonetheless, a refugee feels better with the current situation (Interviewee 2: "I worry about the future of my daughter, and about our family, but it's better... We are safe here, and that's what matters the most to me").

Most refugees are closely attached to church (Interviewee 2: "I volunteer in this church... I come here every Monday, Tuesday, Wednesday, Thursday, Friday, Sunday... Every day except Saturday, because it doesn't open”). From the church, they are not only able to get financial support (Interviewee 1: "That's not enough. Because rent is getting high, and you have to pay more money. The church helps me every month") and knowledge (Interviewee 3: "this bible college, accepted my, my uh application, and allow me to just come and sit down in the classroom and listen to the teachings like any other student."), but also psychological support (Interviewee 3: "because I know the love of God is so big, is so precious, at this church, we can feel it, to be full of it, because without it, you cannot stay like this for 12 years."), (Interviewee 2: "before I scared. First time. Because I don't know these people, I don't know this country, I don't know anybody... Yeah, but when I came to church, I have many friends") (Interviewee 3: "The church service, I am helping for the translation. I am happy... I am useful in my community, to encourage them, I am encouraging them, I am helping them").

\section{Discussion}

This study aims to use Maslow's hierarchy of needs as a framework to understand whether the Hong Kong government policy toward refugees is able to meet the biological and psychological needs of adult refugees in Hong Kong, and their responses to the policy. Five refugees were interviewed by using the purposive sampling method, that only those who are a refugee, age above 21 and have stayed in Hong Kong over one year were invited.

For the basic needs, most interviewees feel the financial assistance from the government is not enough, as $1,500 \mathrm{HKD}$ is not enough for their rent due to the high rent in $\mathrm{HK}$, except one refugee who feels acceptable as he stayed in a remote area. In addition, most interviewees feel the use of food coupons is not convenient as they can only buy food at certain food retailers and each time, they need to buy food to meet the amount of each coupon, which is 100 HKD per coupon. They are able to receive medical care, but need to queue for a long time at the welfare department to get waived for clinic charge. 
For the psychological needs, most of them would like to work and study, so that they can earn more money, to improve themselves, and to make a contribution to society. However, due to the policy, they are not able to work or to study. Even though a refugee child who is below 18 years old is allowed to study at a primary or a secondary school, but not at a university.

Church is an important resource for these refugees. Besides financial support, the church also provides important psychological support for these refugees, as these refugees are able to get conform and self-worth by assisting the church to serve the community. However, as it should be noted that as these interviewees are recommended by a Christian organization that assists refugees, it should not be overgeneralized to all the Church.

In conclusion, we can find that the basic needs of refugees in Hong Kong are covered in the policy of the Hong Kong SAR government. In addition, the right of education among child refugees is also included in the policy. However, it seems that most interviewees have negative attitudes toward the policy. These findings are consistent with a cross-sectional study conducted by Wong et al. (2017) who survey 374 African ASRs aged 18 years or above in Hong Kong. They found that over $70 \%$ of respondents reported problems for their needs in food, housing and medical services, and the problems of medical services are associated with their depression.

The current findings reveal the current measure is only designed for a short-term instead of a long-term plan, even though some refugees have been staying in Hong Kong for a number of years. The lack of consideration of the psychological needs of refugees may increase their chance of depression, anxiety and anger expression (Saunders et al., 1998; Wong et al., 2017), which may become a social problem in the foreseeable future.

Without appropriate strategies to meet the psychological needs of refugees, some may be forced to endure a risky life to improve their conditions. Furthermore, without a proper plan for the future of refugee children, they may also become problematic teenagers who hold a negative or hostile attitude towards Hongkongers. In addition, they would face the same situation as the adult refugees' experience, that they can't move forward and can only be trapped in the situation without a future for them and their children.

While it is understandable that the Hong Kong SAR government would want to prevent the 'magnet effect' of refugees and the subsequent burden due to being a small city with the highest population density worldwide, the government should provide new and fair policies that do not neglect the psychological needs of refugees in Hong Kong. The Hong Kong SAR government may support NGOs and religious organizations to provide a more systematic programme for the needs of extra income and education among the refugees. The status of refugees does not define who they are, as some of them were a contributor to their societies: a lawyer, doctor, teacher, a pastor, before they were forced to flee. Therefore, the influx of refugees could be beneficial to the society as a whole as well, integrating different thoughts and perceptions from different parts of the globe, becoming a multicultural society that could develop the image of Hong Kong internationally.

Nonetheless, the interpretation of the findings should be cautioned due to the small numbers of interviewees in this study. The findings may not be able to generalize to all refugees in Hong Kong SAR. Nonetheless, the preliminary findings of the current interview provide some information that is worth further examination. Future study can recruit more refugees to examine the robustness of the findings, and to use a quantitative method to examine the extent that the findings can be generalised. Moreover, future studies may recruit more refugees from different demographic backgrounds to further examine their differences, such as any different views from genders, ages, religions and country of origins. 
X. Y. Siah, W. L. Kwok \& P. C. Siah - The Basic and Psychological Needs of Adult Refugees in ...

\section{Acknowledgements}

This research did not receive any specific grant from funding agencies in the public commercial, or not-for-profit sectors.

The authors declare no competing interests.

\section{References}

Bohari, A. A. M., Skitmore, M., Xia, B., \& Teo, M. (2017). Green oriented procurement for building projects: Preliminary findings from Malaysia. Journal of Cleaner Production, 148, 690-700. https://doi.org/10.1016/j.jclepro.2017.01.141

Carvalho, R. (2015). HK parents of refugee children face hurdles to get them an education. Retrieved 15 April 2020, from South China Morning Post website: https://www.scmp.com/news/hongkong/education-community/article/1837307/hk-parents-refugee-children-face-hurdles-getthem.

Cheung, K. (2016). Only 4.7\% of Hongkongers view refugees positively but almost half admit ignorance over issue-Study. Retrieved 15 April 2020, from Hong Kong Free Press HKFP website: https://hongkongfp.com/2016/08/30/only-4-7-of-hongkongers-view-refugees-positivelybut-almost-half-admit-ignorance-over-issue-study/.

Cheung, T. (2016). Put asylum seekers in reception centres and pull out of UN torture convention, says Hong Kong lawmaker. Retrieved 15 April 2020, from South China Morning Post website: https://www.scmp.com/news/hong-kong/politics/article/1925632/put-asylum-seekersreception-centres-and-pull-out-un-torture.

Chiu, J. (2012). New UNHCR head urges Hong Kong to protect refugees and asylum seekers. Retrieved 15 April 2020, from https://www.scmp.com/news/hong-kong/article/1095267/new-unhcrhead-urges-hong-kong-protect-refugees-and-asylum-seekers.

Glaser, B. G. (2001). The grounded theory perspective: Conceptualization contrasted with description. Mill Valley, CA: Sociology Press.

Health in Action (n.d.). Health program for asylum seekers/refugees. Retrieved 15 April 2020, from https://hia.org.hk/en/health-program-for-asylum-seekers-refugees/.

Hong Kong Refugee Advice Centre (2013). Submission to the committee on Economic, Social and Cultural Rights (CESCR): Complementing the third report of the Hong Kong Special Administrative Region (HKSAR). Retrieved from http://tbinternet.ohchr.org/Treaties/CESCR/Shared\%20Documents/CHN/INT_CESCR NG O CHN 14058 E.pdf.

Huberman, M., \& Miles, M. B. (2002). The qualitative researcher's companion. Thousand Oaks, London: Sage.

Lee, D. (2015). Government's new supermarket food voucher scheme popular with asylum seekers | South China Morning Post. Retrieved 15 April 2020, from https://www.scmp.com/news/hongkong/education-community/article/1824456/governments-new-supermarket-food-voucherscheme.

Legislative Council, Hong Kong SAR Government (2006). Minutes of joint meeting of the panel on welfare services and the panel on security- 18 July 2006, LC Paper No. CB (2)3077/05-06. Retrieved from

https://www.google.com/url?sa $=t \& r c t=j \& q=\& e s r c=s \& s o u r c e=w e b \& c d=3 \& c a d=r j a \& u a c t=8 \&$ 
ved=2ahUKEwigz4KvrunoAhXG4XMBHSXUDvMQFjACegQIAxAB\&url=https\%3A\%2F\%2F www.legco.gov.hk\%2Fyro5-

06\%2Fenglish\%2Fpanels\%2Fse\%2Fminutes\%2Fsewso718.pdf\&usg=AOvVawoixnounHwAL G9nd-APp5m8.

Legislative Council, Hong Kong SAR Government (2012). Studies on protections of nonrefoulement claimants in Hong Kong: Should Hong Kong adopt a single, government-led, unified system to process torture claims, refugee claims, and CIDTP claims? (LC Paper No. CB (2)1669/1213(05)).

Legislative Council, Hong Kong SAR Government (2013). Humanitarian assistance for torture claimants, asylum seekers and mandated refugees in Hong Kong, LC Paper No. CB (2)1630/12-13(01). Retrieved from http://www.legco.gov.hk/yr12-13/english/panels/ws/papers/ws0722cb21630-1-e.pdf.

Legislative Council, Hong Kong SAR Government (2014). Situation of mandated refugees, asylum seekers and torture claimants in Hong Kong- 13 January 2013, LC Paper No. CB (2)626/13-14(07). Retrieved from https://www.legco.gov.hk/yr13-14/english/panels/ws/papers/wso113cb2626-7-e.pdf.

Legislative Council, Hong Kong SAR Government (2015). Unified screening mechanism for nonrefoulement claims, LC Paper No. CB (2)1832/14-15(03). Retrieved from http://www.legco.gov.hk/yr14-15/english/panels/se/papers/se20150707cb2-1832-3-e.pdf.

Loper, K. (2010). Human rights, non-refoulement and the protection of refugees in Hong Kong. International Journal of Refugee Law, 22(3), 404-439. https://doi.org/10.1093/ijrl/eeq029

Mathews, G. (2007). Chungking mansions: A center of "low-end globalization". Ethnology, 46(2), 169/183.

McLeod, S. (2007). Maslow's hierarchy of needs. Simply Psychology, 1, 1-8.

Moy, P. (2013). Immigration chief gives Sri Lankan refugee temporary right to work in HK | South China Morning Post. Retrieved 15 April 2020, from https://www.scmp.com/news/hongkong/article/1215575/immigration-chief-gives-sri-lankan-refugee-temporary-right-work-hk.

Poston, B. (2009). Maslow's hierarchy of needs. Surgical Technologist, 41(8), 347-353.

Refugee Concern Network (2013a). Improving the living conditions of protection claimants in Hong Kong: Recommendations from the field. Retrieved from http://www.legco.gov.hk/yr1213/english/panels/ws/papers/ws0722cb2-226-1-e.pdf.

Regan, H. (2016). Asylum seekers struggle to survive in one of the world's most expensive cities. Retrieved 15 April 2020, from https://time.com/4374389/hong-kong-asylum-seekers-migrantsrefugees/.

Saunders, S., Munro, D., \& Bore, M. (1998). Maslow's hierarchy of needs and its relationship with psychological health and materialism. South Pacific Journal of Psychology, 10(2), 15-25. https://doi.org/10.1017/So257543400000833

Security Bureau, Hong Kong SAR Government (2009a). The administration's response to the joint submission of the law society and the bar association to the LegCo panel on security on legal representation for CAT claimants dated 24.9.2009, LC Paper No. CB (2)33/o9-10(01), 9 Oct. 2009, para. 7. Retrieved from https://www.legco.gov.hk/yro8o9/english/panels/se/papers/se0929cb2-33-1-e.pdf.

Security Bureau, Hong Kong SAR Government (2009b). Torture claim screening mechanism: Enhanced mechanism and way forward, LC Paper No. CB (2)370/09-10(03), Nov. 2009, para. 9. Retrieved from https://www.legco.gov.hk/yro9-10/english/panels/se/papers/se1201cb2370-3-e.pdf.

Shum, T. (2011). Refugee protection and spaces: Seeking asylum in Hong Kong. Oxford Monitor of Forced Migration, 1(2), 17. 
X. Y. Siah, W. L. Kwok \& P. C. Siah - The Basic and Psychological Needs of Adult Refugees in ...

The Government of the Hong Kong Special Administrative Region (2017). LCQ3: Humanitarian assistance for non-refoulement claimants. Retrieved 15 April 2020, from https://www.info.gov.hk/gia/general/201702/15/P2017021500554.htm.

The Telegraph (2020). The world's most expensive places to own a home. Retrieved 15 April 2020, from World Economic Forum website:

https://www.telegraph.co.uk/finance/property/international/10675352/The-worlds-10most-expensive-cities-to-buy-property.html.

Tinoco, M. (2015). Photos: These refugees stuck in Hong Kong can't get asylum, can't work, and can't leave. Retrieved 15 April 2020, from Quartz website: https://qz.com/477021/photos-theserefugees-stuck-in-hong-kong-cant-get-asylum-cant-work-and-cant-leave/.

United Nations High Commission for Refugees (2018). Global trends-Forced displacement in 2018. Retrieved 15 April 2020, from UNHCR Global Trends 2018 website: https://www.unhcr.org/globaltrends2018/.

Vision First (2013). Social welfare tender reference SWD/ Too2/ 2011. Retrieved from http://www.vfnow.org/uploads/SWD-ISS-Service-Specifications.pdf.

Vision First (2016). Refugees abuse welfare, or welfare abuses refugees? Retrieved 15 April 2020, from http://www.vfnow.org/9766/refugees-abuse-welfare-welfare-abuses-refugees/.

Wong, W. C. W., Cheung, S., Miu, H. Y. H., Chen, J., Loper, K. A., \& Holroyd, E. (2017). Mental health of African asylum-seekers and refugees in Hong Kong: Using the social determinants of health framework. BMC Public Health, 17(1), 153. https://doi.org/10.1186/s12889-016-3953-5 